\title{
Echocardiographic Findings in Friedreich's Ataxia
}

\author{
H. F. GATTIKER, A. DAVIGNON, A. BOZIO, J. BATLLE-DIAZ, \\ G. GEOFFROY, B. LEMIEUX. AND A. BARBEAU
}

SUMMARY: Echocardiographic examination of 21 patients with Friedreich's ataxia (age 7 to 28 years) showed cardiac abnormalities in $90 \%$ of the cases. They were characterized by varying degrees of septal hypertrophy in $81 \%$, left ventricular free wall hypertrophy in $61 \%$, and a slight reduction of left ventricular internal dimension in $57 \%$ of the cases. Asymmetric septal hypertrophy (ASH) with a septallleft ventricular free wall ratio of over 1.3 was found in $29 \%$ of the cases, and systolic anterior motion (SAM) of the mitral valve in three patients. Two other patients showed evidence of a different type of cardiomyopathy with marked symmetric left ventricular hypertrophy and marked left ventricular enlargement.

RÉSUMÉ: L'examen échocardiographique de 21 parients avec ataxie de Friedreich (âge 7 à 28 ans) montre des anomalies dans $90 \%$ des cas. Ces anomalies incluent des degrés divers d'hypertrophie septale (81\%), d'hypertrophie de la paroi libre du ventricule gauche $(61 \%)$ et une légère réduction des dimensions ventriculaires internes dans $57 \%$ des cas. Une hypertrophie septale asymmétrique avec un rapport septum/paroi ventriculaire gauche libre dépassant 1.3, furent trouvés chez $29 \%$ des cas et un mouvement antérieur en systole de la valvule mitrale chez trois patients. Deax autres patients montrent cependant un type différent de cardiomyopathie avec hypertrophie ventriculaire gatuche symmétrique marquée et agrandissement da ventricule gauche.

From the Centre Hospitalier de l'Université de Sherbrooke; the Hopital Ste-Justine; and the Clinical Research Institute of Montreal.

Reprint requests for the complete supplement on Friedreich's ataxia to: Dr. André Barbeau, Clinical Research Institute of Montreal, 110 Pine Avenue West, Montreal, H2W IR7 Quebec, Canada.

\section{INTRODUCTION}

Echocardiography is a diagnostic method utilizing ultrasound to measure dimensions of various cardiac structures and to track their motions faithfully. It has become an accepted diagnostic tool in cardiology for the non-invasive assessment of cardiac size and function (Feigenbaum, 1972; Lalani, 1976).

Cardiac involvement is found in up to $55 \%$ of cases with Friedreich's ataxia (Boyer et al., 1962). Echocardiography therefore seems to be a promising method for non-invasive detection and evaluation of possible cardiac abnormalities in patients with Friedreich's ataxia.

\section{SUBJECTS AND METHODS}

Echocardiographic examination was performed as part of a cooperative study of patients with Friedreich's ataxia. There was no selection of patients because of suspected cardiac involvement. Satisfactory echocardiographic records were available from 21 patients who were divided into two groups: thirteen individuals (age 7 to 16 years) formed a group of pediatric patients with Friedreich's ataxia and were compared with a group of 28 normal subjects (age 7 to 16 years) without heart disease. Eight individuals (age 17 to 28 years) formed a group of adult patients with Friedreich's ataxia whose echocardiographic data were compared with normal published values (Henry, 1973; Popp, 1969). All these patients were from Groups Ia and Ib.

Echocardiograms were obtained and analyzed in a standard fashion according to the technique described (Feigenbaum, 1972; Henry et al., 1973; Popp et al., 1969). A Smith-
French Ekoline 20 echocardiograph with a $2.25 \mathrm{MHz} \mathrm{Cl} 4$ transducer focused at $7.5 \mathrm{~cm}$. and a Honeywell 1856 or a Cambridge recorder were used.

The following echocardiographic parameters were utilized:

$$
\begin{aligned}
& \text { LVID(D) - Left ventricular internal } \\
& \text { dimension in diastole } \\
& \text { LVWT(D) - Left ventricular free wall } \\
& \text { thickness in diastole } \\
& \text { ST(D) - Interventricular septal } \\
& \text { thickness in diastole } \\
& \text { ST(D)/LVWT(D) } \\
& \text { - Septal thickness/ } \\
& \text { posterior left ventricular } \\
& \text { free wall thickness ratio }
\end{aligned}
$$

An estimation of the left ventricular volume in diastole ( $\left.\mathrm{LVVol}_{(\mathrm{D})}\right)$ was obtained by $\left.\mathrm{LVID}_{(\mathrm{D})}\right)^{3}$. The ejection fraction was calculated by:

$$
\begin{aligned}
& E F=\frac{\left(L V I D(D)^{3}-L V I D(S)^{3}\right) \times 100}{{\text { LVID }(D)^{3}}^{3}} \\
& \text { LVID(S) }-\begin{array}{l}
\text { Left ventricular } \\
\text { internal dimension in systole }
\end{array}
\end{aligned}
$$

Mean value \pm S.D. (standard deviation) were calculated for the echocardiographic data of the group of pediatric patients and normals, and statistical analysis was done by a Student's t-test.

\section{RESULTS \\ Age and body surface area}

There was no significant difference in age and body surface area between the group of pediatric patients with Friedreich's ataxia and normal subjects, age 7 to 16 years (Table 1). 
TABLE 1

ANTHROPOMETRIC AND ECHOCARDIOGRAPHIC DATA

\begin{tabular}{|c|c|c|}
\hline & $\begin{array}{c}\text { Patients with } \\
\text { Friedreich's ataxia } \\
(N=13)\end{array}$ & $\begin{array}{l}\text { Normal subjects } \\
\quad(N=28)\end{array}$ \\
\hline Age (years) & $\begin{array}{l}11.9 \pm 2.8 \\
(\text { range } 7-16)\end{array}$ & $\begin{array}{c}10.5 \pm 2.9 \\
(\text { range } \\
7-16)\end{array}$ \\
\hline BSA $\left(m^{2}\right)$ & $1.06 \pm 0.19$ & $1.13 \pm 0.28 \mathrm{NS}$ \\
\hline $\operatorname{LVID}_{(\mathrm{D})} \mathrm{I} \quad\left(\mathrm{cm} / \mathrm{m}^{2}\right)$ & $3.18 \pm 0.83$ & $3.85 \pm 0.72$ * \\
\hline $\left.\operatorname{LVWT}_{(D)}\right)^{I}\left(\mathrm{~cm} / \mathrm{m}^{2}\right)$ & $0.89 \pm 0.24$ & $0.62 \pm 0.14 \star \star \star$ \\
\hline$S T(D) I\left(\mathrm{~cm} / \mathrm{m}^{2}\right)$ & $1.01 \pm 0.31$ & $0.73 \pm 0.18$ ** \\
\hline ST/LVWT & $1.13 \pm 0.21$ & $1.18 \pm 0.13 \mathrm{NS}$ \\
\hline $\mathrm{LWOl}_{(\mathrm{D})} \mathrm{I}\left(\mathrm{ml} / \mathrm{m}^{2}\right)$ & $35.18 \pm 15.66$ & $65.77 \pm 12.18 \cdot \star \star$ \\
\hline $\mathrm{EF}(\%)$ & $71.90 \pm 17.70$ & $74.66 \pm 7.26 \mathrm{NS}$ \\
\hline PWMV $(\mathrm{cm} / \mathrm{sec})$ & $5.15 \pm 1.23$ & $5.05 \pm 0.76 \mathrm{NS}$ \\
\hline
\end{tabular}

Abbreviations:

$\star$ : $P<0.05$

$\star \star: P<0.01$

NS: Not significant

BSA: Body surface area

LVIO $(D)$ I: Left ventricular internal dimension in diastole index

LVWT $(D)$ I: Left ventricular free wall thickness in diastole index

ST $(D)$ I: Interventricular septal thickness in diastole index

ST/LVWT: Septal thickness/posterior wall thickness ratio in diastole

LVVol$_{(D)} \mathrm{I}$ : Left ventricular volume in diastole index

EF: Ejection fraction

PWMV: Posterior wall maximal velocity

\section{Echocardiographic data}

Left ventricle and interventricular septum

Individual values of patients with Friedreich's ataxia were compared with normal values (Mean valuesS.D. [standard deviation] were accepted as the range of normal values.) and showed that $13 / 21$ patients had an increase in left ventricular free wall thickness, and 17/21 pa- tients an increase in interventricular septal thickness. Asymmetric septal hypertrophy $(\mathrm{ASH})$ with a septal/left ventricular free wall ratio over 1.3 (range: 1.33 to 1.7 , mean 1.43) was found in $6 / 21$ patients with Friedreich's ataxia. Twelve/21 patients showed a decrease in left ventricular internal dimension.

Two patients with Friedreich's ataxia, age 8 and 7 showed an in- crease in left ventricular internal dimension index $\left(4.64\right.$ and $\left.5.16 \mathrm{~cm} / \mathrm{m}^{2}\right)$ and a marked increase in left ventricular free wall thickness index (1.5 and $1.32 \mathrm{~cm} / \mathrm{m}^{2}$ ) with a septal/left ventricular free wall ratio of 1.1 and 1.0 .

Comparison of two groups of pediatric subjects are summarized in Table 1 and Figures 1 and 2.

The mean $\mathrm{LVWT}_{(\mathrm{D})}$ index was $43 \%(p<0.01)$ larger in patients with Friedreich's ataxia than in normal subjects. The mean $S T_{(D)}$ index was $38 \%(\mathrm{p}<0.01)$ thicker in patients with Friedreich's ataxia than in normal subjects. The mean $\left.S T_{(D)} / L\right) W T_{(D)}$ ratio showed no significant difference between patients with Friedreich's ataxia and normal subjects. The mean $\mathrm{LVID}_{(\mathrm{D})}$ index was $17 \%(\mathrm{p}<0.05)$ smaller in patients with Friedreich's ataxia than in normal subjects.

The estimated mean LVVol(D) was $46 \%(p<0.01)$ smaller in patients with Friedreich's ataxia than in normal subjects.

There was no significant difference in the estimated mean EF and mean PWMV between patients with Friedreich's ataxia and normal subjects.

\section{Mitral valve}

Systolic anterior motion (SAM) was found in three patients (Table II, Figures 3 and 4). Mitral valve prolapse was found in one patient (No. 23). Two patients, age 15 and 12 , were normal on echocardiographic examination.

\section{DISCUSSION}

Echocardiographic examination of 21 patients with Friedreich's ataxia showed evidence of cardiac abnormalities in $90 \%$ of the cases. These abnormalities were: varying degrees of interventricular septal hypertrophy in $81 \%$, left ventricular free wall hypertrophy in $62 \%$, and slight reduction of the left ventricular internal dimension in $57 \%$.

Asymmetric septal hypertrophy (ASH) with a septal/left ventricular free wall ratio over 1.3 was found in $29 \%$ of the cases.

Three patients showed evidence of systolic anterior motion (SAM) of the mitral valve. They all had a 

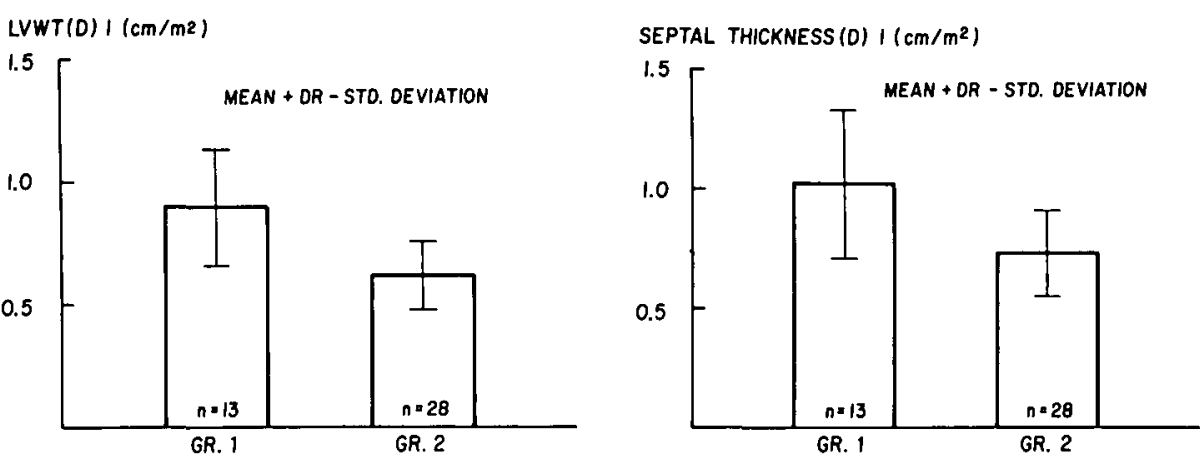

Figures $l a \& l b-$ Echocardiographic determination of LVWT(D)I (left) and ST(D)I (right) in 13 patients with Friedreich's ataxia (GR 1) and 28 normal subjects (GR 2).
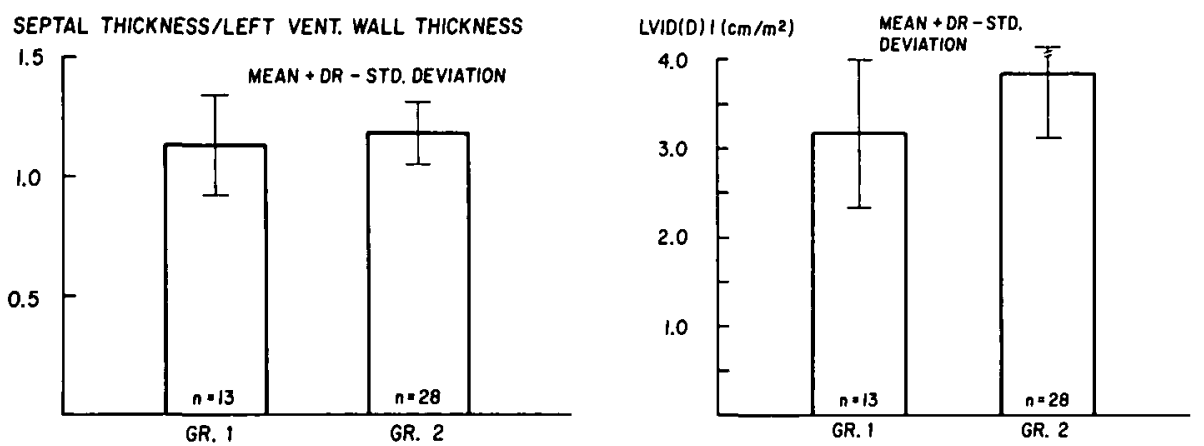

Figures $2 a \& 2 b$ - Echocardiographic determination of ST(D)/LVWT(D) (left) and LVID(D)I (right) in 13 patients with Friedreich's ataxia (GR 1) and 28 normal subjects (GR 2). marked septal hypertrophy, but only two had ASH of a minor degree. The third patient had symmetric left ventricular hypertrophy. The interventricular septum contracted poorly in all three patients, and an echocardiographic diagnosis of probable obstructive cardiomyopathy was made in the two patients with ASH. Obstruction could not be ruled out completely in the third patient with symmetric left ventricular hypertrophy. Hemodynamic examination showed evidence of a pressure gradient within the left ventricle of $60 \mathrm{mmHg}$ at rest in one patient and of 38 $\mathrm{mmHg}$ only on provocation with isoproterenol in the other patients, who showed ASH. No gradient, either at rest or on provocation, was present in the patient without ASH.

It should be noted that two of our youngest patients with Friedreich's ataxia showed evidence of a different type of cardiomyopathy characterized by marked left ventricular enlargement and concentric left ventricular hypertrophy with a normal/left ventricular free wall ratio. It is not known if this represents a different type of cardiomyopathy or only a different stage in the development of the usual

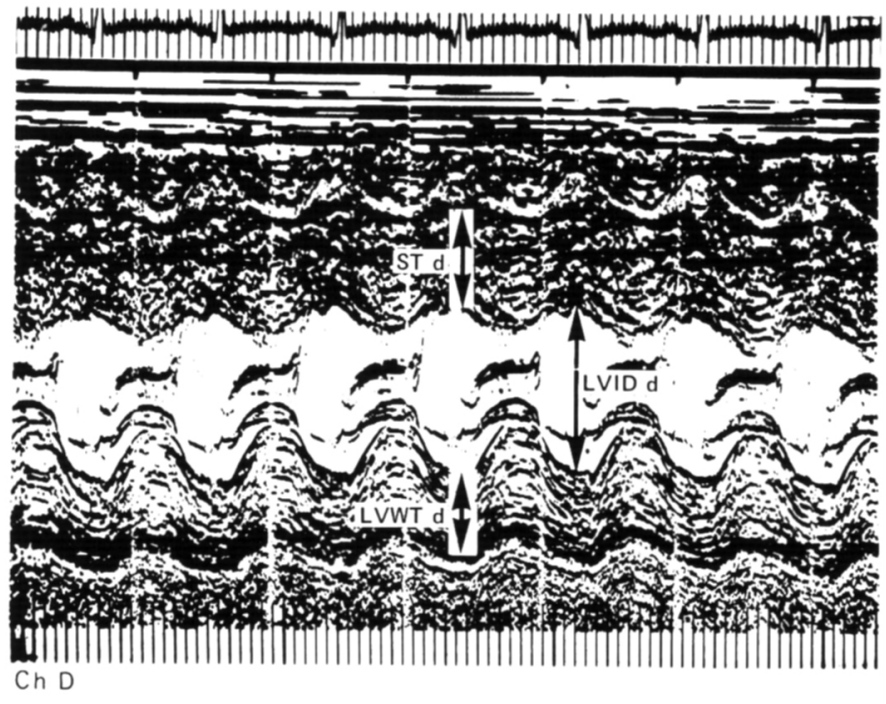

Figure 3 - Left ventricular echocardiogram from patient No. 18 (Group Ia) (Ch. D.) showing asymmetric septal hypertrophy $(\mathrm{ASH})$ of slight degree. LVID(D) - left ventricular internal dimension in diastole. ST(D) - Septal thickness in diastole. LVWT(D) - Left ventricular free wall thickness in diastole.

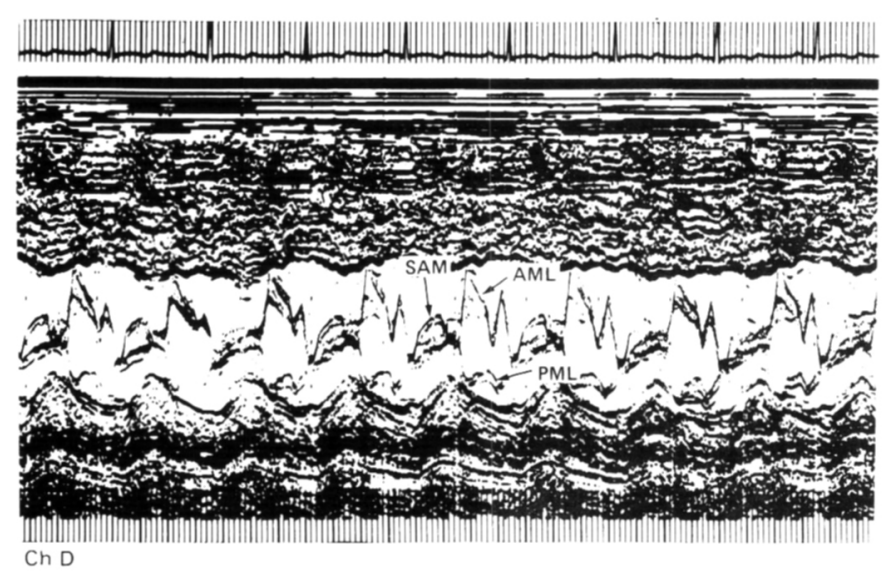

Figure 4-Mitral valve echocardiogram from the same patient. No. 18, Group Ia.(Ch.D), showing systolic anterior motion (SAM) of the anterior leaflet of the mitral valve. SAM Systolic anterior motion of the anterior mitral valve leaflet. AML - Anterior mitral valve leaflet. PML - Posterior mitral valve leaflet. 
TABLE 2

ECHOCARDIOGRAPHIC DATA OF PATIENTS

WITH SYSTOLIC ANTERIOR MOTION (SAM) OF THE MITRAL VALVE

$\begin{array}{lccc}\text { Patient } & \begin{array}{c}\text { S.T. } \\ \text { Ho. ig }\end{array} & \begin{array}{c}\text { Ch. O. } \\ \text { No. } 20\end{array} & \begin{array}{c}\text { G.M. } \\ \text { No. } 35\end{array} \\ \text { Age (years) } & 13 & 14 & 12 \\ \begin{array}{l}\text { ST (D) I }\left(\mathrm{cm} / \mathrm{m}^{2}\right) \\ \text { ST/LVWT }\end{array} & 1.32 & 1.16 & 1.17 \\ \begin{array}{l}\text { Septal thickening (x) } \\ \text { in systole }\end{array} & 1.19 & 1.36 & 1.5 \\ & 16.7 & 13.3 & 16.7\end{array}$

cardiomyopathy found in the other patients with Friedreich's ataxia.

The only report on echocardiographic examination of patients with Friedreich's ataxia that we could find was an abstract by E. R. Smith (1975), who examined 10 patients with Friedreich's ataxia and found ASH in four patients with a septal/posterior wall ratio of 1.4 to 1.9 (mean: 1.66).

In conclusion, echocardiography appears capable of providing qualitative and quantitative information on abnormalities of left ventricular di- mension and function and on mitral valve motion. Echocardiographic screening of family members of patients with Friedreich's ataxia should help to detect and define more precisely early cardiac involvement and aid in clarifying the relationship between cardiac and neurological manifestations of this disease. Because of its non-invasive nature, echocardiography can be used repeatedly in the same patient. Echocardiographic follow-up examination of patients with Friedreich's ataxia should give valuable information on the natural history and prognosis of established cardiomyopathy.

\section{ACKNOWLEDGMENTS}

The authors wish to express their appreciation to Dr. F. Winsberg of the Department of Diagnostic Radiology. The Montreal General Hospital, Montreal, Quebec, for his valuable cooperation in this study.

We also want to thank Mrs. Marguerite Megelaz, Mr. André Boileau, Mr. Gilles Ducharme, and Mr. Rosaire Chouinard for their skillful technical assistance. The studies reported in this paper were supported in part by L'Association Canadienne de l'Ataxie de Friedreich and the Medical Research Council of Canada.

\section{REFERENCES}

BOYER, S. H., CHISHOLM, A. W., and McKUSICK, V. A. (1962). Cardiac aspects of Friedreich's ataxia. Circulation, 25, 493-505.

FEIGENBAUM, H. (1972). Clinical applications of echocardiography. Progr. Cardiovasc. Dis., 14, 531-558.

HENRY, W. L., CLARK, C. E., and EPSTEIN, S. E. (1973). Echocardiographic identification of the pathognomonic anatomic abnormality of IHSS. Circulation, 47, 225-233.

LALANI, A. V., and LEE, S. J. K. (1976). Clinical echocardiography - An overview. Canad. Med. Ass. J., 114, 46-54.

POPP, R. I.. WOLFE, S. B., HIRATA, T., and FEIGENBAUM, H. (1969). Estimation of right and left ventricular size by ultrasound. Amer. J. Cardiol., 24, 523.

SMITH, E. R., FLEMINGTON, C. S., HEFFERNAN, L. P., and SANGALANG, V. E. (1975). Echocardiography in Friedreich's ataxia. Clin. Res., 23, No. 3. 